\title{
Relation of BAALC and ERG Gene Expression with Overall Survival in Acute Myeloid Leukemia Cases
}

\author{
Reham A Rashed ${ }^{1 *}$, Dalia Y Kadry ${ }^{1}$, Maha EL Taweel ${ }^{1}$, Nahed Abd El Wahab ${ }^{1}$, \\ Thoreya Abd El Hameed ${ }^{2}$
}

\begin{abstract}
Background: The objectives of this study were to evaluate the expression of brain and acute leukemia, cytoplasmic (BAALC) gene and erythroblast transformation-specific related gene (ERG) in de novo cases of acute myeloid leukemia (AML) and identify roles in disease progression and outcome. Materials and Methods: This study included 50 newly diagnosed AML patients, along with 10 apparently healthy normal controls. BAALC and ERG expression was detected in the bone marrow of both patients and controls using real-time RT-PCR. Results: BAALC and ERG expression was detected in $52 \%$ of cases but not in any controls. There was a statistically significant correlation between BAALC and ERG gene expression and age (p- value $=0.004$ and 0.019, respectively). No statistical significance was noted for sex, lymphadenopathy, hepatomegaly, splenomegaly, other hematological findings, immunophenotyping and FAB sub-classification except for ERG gene and FAB (p-value=0.058). A statistical significant correlation was found between response to treatment with ERG expression (p-value $=0.028)$ and age $(p$-value $=0.014)$. A statistically significant variation in overall survival was evident with patient age, BM blast cells, FAB subgroups, BAALC and ERG expression (p-value $=<0.001,0.045,0.041,<0.008$ and 0.025 respectively). Conclusions: Our results suggest that BAALC and ERG genes are specific significant molecular markers in AML disease progression, response to treatment and survival.
\end{abstract}

Keywords: BAALC - ERG - AML - RT-PCR

Asian Pac J Cancer Prev, 16 (17), 7875-7882

\section{Introduction}

Acute myeloid leukemia (AML) is a cytogenetically and molecularly heterogeneous disease characterized by clonal proliferation of myeloid precursors and maturation arrest, with accumulation of acquired genetic alterations in hematopoietic progenitor cells that disturb normal mechanisms of cell growth, proliferation and differentiation (Dohner 2005). The precise molecular origins of AML are unknown. The pathophysiologic mechanisms are multiple, act in concert, and probably are distinct in different types of AML. Inherited genetic predisposition and environmental mutagens such as radiation, drugs and other toxins all play a role in the development of AML (Solomon and Malkovska, 2005).

Leukemogenesis in AML is a heterogeneous, multistep process, single genetic change is insufficient to cause AML by itself, and at least two different mutations must occur in the hematopoietic progenitor cell to transform it into a malignant cell initiating the development of a clonal AML blast population (Mrozek et al., 2007). The resulting molecular alterations disrupt almost every facet of cell transformation. These processes include the inappropriate proliferation in the absence of normal growth signals, indefinite self-renewal in a manner analogous to a stem cell, escape from programmed cell death, inhibition of differentiation, aberrant cell cycle checkpoint control, genomic instability and multi-organ dissemination of leukemic cells (Lichtman and Sternberg, 2005).

The brain and acute leukemia, cytoplasmic (BAALC), which maps on chromosome 8 at $8 \mathrm{q} 22.3$, was originally observed in the neuroderm and its expression was reported as a hematopoietic precursor, such as the early hematopoietic cells of cluster of differentiation 34+( Baldus et al., 2003). BAALC expression was higher in bone marrow compared to blood. In addition, high levels of BAALC expression were present in leukemic blasts in subsets of acute lymphoblastic leukemia (ALL) and AML patients with a normal karyotype (Bienz et al., 2005), it may act as an adverse prognostic factor through prompting proliferation and inhibiting apoptosis in leukemia cells (Bing et al., 2012).

The site and cellular mechanism(s) of the effects of the BAALC gene are unclear, thereby possibly resulting in differentiation failure caused by cell shape, motility and adhesion in the association between cells (Tanner et al., 2001). Subsequent research has shown that the highly expressed BAALC gene is associated with minimal 
residual disease, which leads to a low complete remission (CR) rate and overall survival (OS).

The ERG (ETS related gene 1) gene belongs to the erythroblast transformation-specific (ETS) family of transcription factors, and is located on chromosome 21q22.2 (Oikawa and Yamada, 2003). ERG and other members of the same family are downstream regulators of mitogenic signal transduction pathways. They are key regulators of embryonic development, cell proliferation, differentiation, angiogenesis, inflammation, and apoptosis (Loughran et al., 2008).

ERG, plays an important role in early hematopoiesis and hematopoietic stem cell (HSC) maintenance (Taoudi et al., 2011). ERG is also part of fusion proteins in solid tumors such as prostate cancer (Klezovitch et al., 2008), Ewing Sarcoma (Sorensen et al., 1994) and in acute myeloid leukemia (AML) (Kong et al., 1997).

In acute leukemia, high ERG mRNA expression levels are an independent prognostic factor. Studies have demonstrated that increased ERG expression is associated with poor prognosis in cytogenetically normal AML (Eid et al., 2010) and in adult T-ALL (Baldus et al., 2006).

In this study we aimed to evaluate the expression of BAALC and ERG genes in leukemic cells from newly diagnosed acute myeloid leukemia patients, and correlate data with their significance in disease progression, response to treatment and survival as well as their potential use as target molecules in therapy.

\section{Materials and Methods}

This study was carried out on 50 newly diagnosed acute myeloid leukemia cases, who presented to the medical oncology clinics, National Cancer Institute, Cairo University, during the period from February 2010 to March 2012 with ten healthy age and sex matched controls were included in the study.

A Written informed consent was approved by the Institutional Review board (IRB) ethical committee of the NCI which follows the rules of Helsinki IRB was obtained from each patient before starting the data collection. For the sake of patient's privacy, they were given code numbers.

\section{Morphological and immunophenotypic analysis}

Morphologic analysis of bone marrow (BM) smear preparations was carried out at the Hematology Unit of the Clinical Pathology Department at the National Cancer Institute, Cairo University, Egypt.

Abone marrow aspirate is part of the routine diagnostic work-up of a patient with suspected AML. The panel considers a marrow trephine biopsy optional, but it should be performed in patients with a dry tap.

Blood and marrow smears are morphologically examined using a May-Grünwald Giemsa or a WrightGiemsa stain. It is recommended that at least 200 leukocytes on blood smears and 500 nucleated cells on marrow smears be counted, with the latter containing spicules. For a diagnosis of AML according to WHO proposal (Vardiman et al., 2009), a marrow or blood blast count of $\geq 20 \%$ or more is required, except for AML with $\mathrm{t}(15 ; 17), \mathrm{t}(8 ; 21)$, inv.(16) or $\mathrm{t}(16 ; 16)$, and some cases of erythroleukemia. Myeloblasts, monoblasts, and megakaryoblasts are included in the blast count. In AML with monocytic or myelomonocytic differentiation, monoblasts and promonocytes, but not abnormal monocytes, are counted as blast equivalents. Erythroblasts are not counted as blasts except in the rare instance of pure erythroid leukemia.

Pretreatment BM samples were centrally collected and stored. Samples were enriched for the blast fraction by density-gradient centrifugation (Ficoll-Hypaque Plus; Amersham Biosciences, Uppsala, Sweden) and stored in liquid nitrogen.

Immunophenotyping of fresh bone marrow samples was performed for all cases using flow cytometric analysis (Partec III from DAKO cytomation) (on routine basis), on marrow blast cells with a panel of monoclonal antibodies, purchased from DAKO ( Denmark), including FITC and PE conjugated CD13, CD33 and MPO. Specific isotype controls for FITC and PE conjugated monoclonal antibodies were used. Results were expressed as percentage of cells showing positive expression.

\section{RNA Isolation and Complementary DNA Synthesis}

Pretreatead BM samples were available from 50 AML patients and 10 healthy controls. Bone marrow mononuclear cells (BMMCs) were extracted from 1-2 ml EDTA blood cells, (they were obtained by gradient density centrifugation using Ficoll-Hypaque 1077 (Sigma). Cell pellets were kept at $-80^{\circ} \mathrm{C}$ until RNA extraction was performed. Extraction of total RNA from mononuclear cells was carried out using the QIA-amp RNA blood Mini Kit (QIAGEN, Hilden, Germany) following the manufacturer's instructions. The concentration and purity of RNA was measured at $260 \& 280 \& 230 \mathrm{~nm}$ using Nano Drop 2000/2000c Spectrophotometer (Thermo Scientific, USA). Ratio of A260/A280 = $1.8-2.1$ and A260/A230 = 1.8 - 2.1 indicates highly pure RNA.

Extracted RNA was reverse transcribed into Complementary DNA (c DNA) using TaqMan ${ }^{\circledR}$ RNA reverse Transcription Kit (Applied Bio-system, USA) according to the TaqMan RNA Assay protocol. The PCR reactions were carried out in a total volume of $20 \mathrm{ul}(10 \mathrm{ul}$ mix+10ul extracted RNA), the thermal cycle reaction was as follows: 10 minutes at $25^{\circ} \mathrm{C}$ (for incubation), $37^{\circ} \mathrm{C}$ for 2 hours for reverse transcription, $85^{\circ} \mathrm{C}$ for 5 seconds to stop the reaction. The main PCR cycles were repeated 40 times.

Quantitative real-time reverse - transcription - polymerase chain reaction (RT-PCR) amplification of $B A A L C, E R G$

Complementary DNA and amplification of nucleic acid by ( One Step RT-PCR sequence detection system supplied by Applied Bio-systems AB Co. ) using the following sequence : The RT-PCR primers and Taqman probes for BAALC and ERG genes sets were developed using Primer Express ${ }^{\circledR}$ software, using the following primers as follows:

BAALC Forward primer
5'GCCCTCTGACCCAGAAACAG
BAALC Reverse primer
5'CTTTTGCAGGCATTCTCTTAGCA


BAALC Probe

5'-FAM-CTCTTTTAGCCTCTGTCTGAAGGCCAT-

TAMRA

ERG Forward primer

5'CACGAACGAGCGCAGAGTTA

ERG Reverse primer

5'CTGCCGCACATGGTCTGTAC

ERG probe

5-FAM-CGTGCCAGCAGATCCTACGCTATGGTAMRA

Commercially available primers and probes for GAPDH and $\beta$-Actin mRNA were used for normalization (Applied Bio-systems). PCR reactions were performed on The Applied Bio-system Step One Plus Real- Time PCR Systems (Applied Bio-systems). DNA replication was detected with dual labeled fluorogenic hybridization probes using the following technique:

The PCR reactions were carried out in a total volume of $25 \mathrm{ul}$ for each reaction of which 5ul of c DNA was used 20ul of universal Taqman master mix + forward $\&$ reverse primer $\& 1 / 2 \mathrm{ul}$ of which are the fluorogenic probes .The reaction was carried out using the following thermal cycle reaction 2 minutes at $25^{\circ} \mathrm{C}, 95^{\circ} \mathrm{C}$ for $10 \mathrm{~min} 95^{\circ} \mathrm{C}$ for 15 seconds $60^{\circ} \mathrm{C}$ for $1 \mathrm{~min}$.

The relative expression of both genes was determined using comparative CT method for the samples in relation to expression of GAPDH $(\Delta \mathrm{CT}=$ gene $\mathrm{CT}-\mathrm{GAPDH}$ $\mathrm{CT})$. If the gene expression failed to reach the software threshold sample is considered negative \& if GAPDH amplification fails the sample was omitted. The CT is reversely related to the amount of target molecules in the reaction.

\section{Data analysis}

The threshold cycle data $(\mathrm{Ct})$ and baselines were determined using auto settings. The relative quantification of BAALC and ERG expression was calculated using the comparative CT method $\left(2^{-\Delta \Delta \mathrm{CT}}\right)$ where $\Delta \Delta \mathrm{CT}$ is the difference of $\Delta \mathrm{CT}$ value between the leukemia and the control $(\Delta \Delta \mathrm{CT}=\Delta \mathrm{CT}$ leukemia gene $-\Delta \mathrm{CT}$ control gene), and $\Delta \mathrm{CT}$ is the difference of $\mathrm{CT}$ value between the target (gene) and endogenous reference (GAPDH) gene $(\triangle \mathrm{CT}=\mathrm{CT}$ Target gene $-\mathrm{GAPDH}$ gene $)$.

\section{Statistical analysis:}

Data management and analysis were performed using the Statistical Analysis System (SPSS) software. The study of prevalence of the studied marker among the studied groups was done by using Fisher Exact test. Comparison of groups with respect to numerical variables was done using the Mann Whitney test.

All p-values were two sided. P-values $\leq 0.05$ were considered significant. Sensitivity, specificity and diagnostic accuracy were the validity measures used for testing the studied parameter as diagnostic tools for AML.

\section{Results}

Fifty de novo adult acute myeloid leukemia patients and ten healthy age and sex matched controls were included in this study who presented to the National Cancer Institute, in the period between February 2010 and March 2012. They were 26 females (26/50) (52\%) and 24 males (24/50) (48\%), their ages ranged from 16 to 72 with a median of 38 years. The clinico-hematological characteristics, FAB classification and immunophenotyping of the 50 adult AML patients included in this study are shown in Table1.

BAALC and ERG m-RNA was studied in the $50 \mathrm{AML}$ patients and 10 healthy controls, none of the studied controls expressed BAALC or ERG m-RNA transcript. We defined our patient subgroups as high and low expressers for each gene. The median was taken as a cut off value (10.4 for BAALC and 65.9 for ERG) below it the patient is considered as low expresser and above it, the patient is high expresser. For BAALC gene, 26/50 (52\%) patients were high expressers compared to 24/50 (48\%) were low BAALC expressers. As regarding ERG gene, 26/50 (52\%) patients were high expressers compared to $24 / 50$ (48\%) were low expressers.

Table 2. Represents the hematological parameters, FAB classification and immunophenotyping in relation to high and low expressions for BAALC and ERG genes. There was no statistically significant difference between high and low expressions for both genes except with age ( $p=0.004$ and 0.019 respectively) and with the different subtypes of FAB classification regarding ERG expression $(\mathrm{p}=0.058)$ (Figures 1,2).

Regarding the complete response rate, in our study, CR

Table 1. Clinical and Hematological Characteristics of 50 adult AML Patient

\begin{tabular}{|c|c|c|c|}
\hline \multicolumn{3}{|l|}{ Parameter } & Total No (\%) \\
\hline \multirow{2}{*}{\multicolumn{2}{|c|}{ Age (Years) }} & $<45$ & $29 / 50(58 \%)$ \\
\hline & & $\geq 45$ & $21 / 50(42 \%)$ \\
\hline \multirow{2}{*}{\multicolumn{2}{|c|}{ Sex }} & Female & $26 / 50(52 \%)$ \\
\hline & & Male & $24 / 50(48 \%)$ \\
\hline \multirow{3}{*}{\multicolumn{2}{|c|}{ Signs }} & Lymphadenopathy & $15 / 50(30 \%)$ \\
\hline & & Splenomegaly & $21 / 50(42 \%)$ \\
\hline & & Hepatomegaly & $25 / 50(50 \%)$ \\
\hline \multirow{2}{*}{\multicolumn{2}{|c|}{ WBCs (x 109/L) }} & $<50$ & $27 / 50(54 \%)$ \\
\hline & & $\geq 50$ & $23 / 50(46 \%)$ \\
\hline \multirow{2}{*}{\multicolumn{2}{|c|}{$\mathrm{HB}(\mathrm{gm} / \mathrm{dL})$}} & $<8$ & $34 / 50(68 \%)$ \\
\hline & & $\geq 8$ & $16 / 50(32 \%)$ \\
\hline \multirow{2}{*}{\multicolumn{2}{|c|}{ Platelets (x 109/L) }} & $<50$ & $34 / 50(68 \%)$ \\
\hline & & $\geq 50$ & $16 / 50(32 \%)$ \\
\hline \multirow{2}{*}{\multicolumn{2}{|c|}{ Peripheral blood blasts }} & $<50$ & $31 / 50(62 \%)$ \\
\hline & & $\geq 50$ & $19 / 50(38 \%)$ \\
\hline \multirow{2}{*}{\multicolumn{2}{|c|}{ Bone marrow cellularity }} & Hypercellular & $39 / 50(78 \%)$ \\
\hline & & Normocellular & $11 / 50(22 \%)$ \\
\hline \multirow{2}{*}{\multicolumn{2}{|c|}{ BM blasts }} & $<75 \%$ & $22 / 50(44 \%)$ \\
\hline & & $\geq 75 \%$ & $28 / 50(56 \%)$ \\
\hline \multirow{5}{*}{\multicolumn{2}{|c|}{ FAB Classification: }} & M0 & $08 / 50(16 \%)$ \\
\hline & & M1 & $20 / 50(40 \%)$ \\
\hline & & M2 & $16 / 50(32 \%)$ \\
\hline & & M4 & $05 / 50(10 \%)$ \\
\hline & & M5 & $01 / 50(02 \%)$ \\
\hline \multirow[t]{2}{*}{ Phenotype: } & \multicolumn{2}{|l|}{ Myeloid } & $44 / 50(88 \%)$ \\
\hline & \multicolumn{2}{|c|}{ Myeloid with monocytic element } & $06 / 50(12 \%)$ \\
\hline \multirow[t]{2}{*}{ CD34 } & & $34 / 50(68 \%)$ \\
\hline & \multicolumn{2}{|l|}{ Negative } & $16 / 50(32 \%)$ \\
\hline \multirow[t]{2}{*}{ CD117 } & \multicolumn{2}{|l|}{ Positive } & $31 / 50(62 \%)$ \\
\hline & \multicolumn{2}{|l|}{ Negative } & $19 / 50(38 \%)$ \\
\hline
\end{tabular}

FAB (French American British), WBC (White blood cells), HB (Hemoglobin), BM (Bone marrow) 
Table 2. Different Clinical and Hematological Parameters with FAB subtypes and Immunophenotyping in Relation to BAALC and ERG Genes Expression

\begin{tabular}{|c|c|c|c|c|c|c|c|}
\hline & \multicolumn{3}{|c|}{ BAALC Expression } & \multicolumn{4}{|c|}{ ERG Expression } \\
\hline & Low Expression & High Expressiom & Total & P.value Low Expression & High Expression & Total & P.value \\
\hline AGE(Years) & & & & $0.004 *$ & & & $0.019 *$ \\
\hline$<45$ & $19 / 29(65.5 \%)$ & $10 / 29(34.5 \%)$ & $29(58 \%)$ & $18 / 29(62.1 \%)$ & $11 / 29(37.9 \%)$ & $29(58 \%)$ & \\
\hline$\geq 45$ & $5 / 21(23.8 \%)$ & $16 / 21(76.2 \%)$ & $21(42 \%)$ & $6 / 21(28.6 \%)$ & $15 / 21(57.7 \%)$ & $21(42 \%)$ & \\
\hline Total & $24(48 \%)$ & $26(52 \%)$ & $50(100 \%)$ & $24(48 \%)$ & $26(52 \%)$ & $50(100 \%)$ & \\
\hline SEX & & & & 0.895 & & & 0.322 \\
\hline Male & $12 / 24(50 \%)$ & $12 / 24(50 \%)$ & $24(100 \%)$ & $14 / 24(58.3 \%)$ & $10 / 24(41.7 \%)$ & $24(100 \%)$ & \\
\hline Female & $12 / 26(46 \%)$ & $14 / 26(54 \%)$ & $26(100 \%)$ & $10 / 26(37.5 \%)$ & $16 / 26(61.5 \%)$ & $26(100 \%)$ & \\
\hline Total & $24 / 50(47.1 \%)$ & $26 / 50(52.9 \%)$ & $50(100 \%)$ & $24 / 50(47.1 \%)$ & $26 / 50(52.9 \%)$ & $50(100 \%)$ & \\
\hline Splenomegaly & & & & 0.947 & & & 0.076 \\
\hline YES & $14 / 29(48.3 \%)$ & $15 / 29(51.7 \%)$ & $29(100 \%)$ & $13 / 21(14.3 \%)$ & 18/21 (85.7\%) & $21(100 \%)$ & \\
\hline NO & $10 / 21(47.7 \%)$ & $11 / 21(52.3 \%)$ & $21(100 \%)$ & $11 / 29(38 \%)$ & $18 / 29(62 \%)$ & $29(100 \%)$ & \\
\hline Total & $24 / 50(47.1 \%)$ & $26 / 50(52.9 \%)$ & $50(100 \%)$ & $24 / 50(47.1 \%)$ & $26 / 50(52.9 \%)$ & $50(100 \%)$ & \\
\hline Hepatomegaly & & & & 0.488 & & & 0.21 \\
\hline YES & $13 / 25(52 \%)$ & $12 / 25(48 \%)$ & $25(100 \%)$ & $14 / 24(58.3 \%)$ & $10 / 24(41.7 \%)$ & $24(100)$ & \\
\hline NO & $11 / 25(44 \%)$ & $14 / 25(56 \%)$ & $25(100 \%)$ & $10 / 26(38.5 \%)$ & $16 / 26(61.5 \%)$ & $26(100)$ & \\
\hline Total & $24 / 50(47.1 \%)$ & $26 / 50(52.9 \%)$ & $50(100 \%)$ & $24 / 50(47.1 \%)$ & $26 / 50(52.9)$ & $50(100)$ & \\
\hline Lymphadenop & pathy & & & 0.971 & & & 0.06 \\
\hline YES & $7 / 14(50 \%)$ & $7 / 14(50 \%)$ & $14(100 \%)$ & $4 / 15(26.7 \%)$ & $11 / 15(73.3 \%)$ & $15(100 \%)$ & \\
\hline $\mathrm{NO}$ & $17 / 36(47.3 \%)$ & $19 / 36(52.7 \%)$ & $36(100 \%)$ & $20 / 35(57.2 \%)$ & $15 / 35(42.8 \%)$ & $35(100 \%)$ & \\
\hline Total & $24 / 50(47.1 \%)$ & $26 / 50(52.9 \%)$ & $50(100 \%)$ & $24 / 50(47.1 \%)$ & $26 / 50(52.9 \%)$ & $50(100 \%)$ & \\
\hline TLC & & & & 0.084 & & & 0.555 \\
\hline$<50.000$ & $16 / 27(40 \%)$ & $11 / 27(60 \%)$ & $27(100 \%)$ & $14 / 27(52 \%)$ & $13 / 27(48 \%)$ & $27(100 \%)$ & \\
\hline$\geq 50.000$ & $8 / 23(34.8 \%)$ & $15 / 23(65.2 \%)$ & $23(100 \%)$ & $10 / 23(43.5 \%)$ & $13 / 23(56.5 \%)$ & $23(100 \%)$ & \\
\hline Total & $24 / 50(47.1 \%)$ & $26 / 50(52.9 \%)$ & $50(100 \%)$ & $24 / 50(47.1 \%)$ & $26 / 50(52.9 \%)$ & $50(100 \%)$ & \\
\hline $\mathrm{HB}$ & & & & 0.423 & & & 0.104 \\
\hline$<8$ & $15 / 39(38.4 \%)$ & $19 / 34(61.6 \%)$ & $34(100 \%)$ & $19 / 34(56 \%)$ & $15 / 34(44 \%)$ & $34(100 \%)$ & \\
\hline$\geq 8$ & $9 / 16(56.2 \%)$ & $7 / 16(43.8 \%)$ & $16(100 \%)$ & $5 / 16(31 \%)$ & $11 / 16(69 \%)$ & $16(100 \%)$ & \\
\hline Total & $24 / 50(47.1 \%)$ & $26 / 50(52.9 \%)$ & $50(100 \%)$ & $24 / 50(47.1 \%)$ & $26 / 50(52.9 \%)$ & $50(100 \%)$ & \\
\hline Plts. & & & & 0.423 & & & 0.846 \\
\hline$<50.000$ & $15 / 39(38.4 \%)$ & $19 / 34(61.6 \%)$ & $34(100 \%)$ & $16 / 34(47 \%)$ & $18 / 34(53 \%)$ & $34(100 \%)$ & \\
\hline$\geq 50.000$ & $9 / 16(56.2 \%)$ & $7 / 16(43.8 \%)$ & $16(100 \%)$ & $8 / 16(50 \%)$ & $8 / 16(50 \%)$ & $16(100 \%)$ & \\
\hline Total & $24 / 50(47.1 \%)$ & $26 / 50(52.9 \%)$ & $50(100 \%)$ & $24 / 50(47.1 \%)$ & $26 / 50(52.9 \%)$ & $50(100 \%)$ & \\
\hline PB Blasts $(\%)$ & & & & 0.119 & & & 0.423 \\
\hline$<50$ & $18 / 32(56.2 \%)$ & $14 / 32(43.8 \%)$ & $32(100 \%)$ & $14 / 32(43,8 \%)$ & $18 / 32(56.2 \%)$ & $32(100 \%)$ & \\
\hline$\geq 50$ & $6 / 18(33.4 \%)$ & $12 / 18(66.6 \%)$ & $18(100 \%)$ & $10 / 18(55.5 \%)$ & $8 / 18(44.5 \%)$ & $18(100 \%)$ & \\
\hline Total & $24(47.1 \%)$ & $26 / 50(52.9 \%)$ & $50(100 \%)$ & $24 / 50(47.1 \%)$ & $26 / 50(52.9 \%) 50$ & $(100 \% 0$ & \\
\hline BM blasts $(\%)$ & & & & 0.433 & & & 0.433 \\
\hline$<75$ & $9 / 22(41 \%)$ & $13 / 22(59 \%)$ & $22(100 \%)$ & $9 / 22(41 \%)$ & $13 / 22(59 \%)$ & $22(100 \%)$ & \\
\hline$\geq 75$ & $15 / 28(53.5 \%)$ & $13 / 28(46.5 \%)$ & $28(100 \%)$ & $15 / 28(53.5 \%)$ & $13 / 28(46.5 \%)$ & $28(100 \%)$ & \\
\hline Total & $24 / 50(47.1 \%)$ & $26 / 50(52.9 \%)$ & $50(100 \%)$ & $24 / 50(47.1 \%)$ & $26 / 50(52.9 \%)$ & $50(100 \%)$ & \\
\hline FAB groups & & & & 0.112 & & & $0.058 *$ \\
\hline M0,M1,M2 & $23 / 24(95.8 \%)$ & $21 / 26(80.7 \%)$ & $44(88 \%)$ & $19 / 24(79.2 \%)$ & 25/26 (96.2) & $44(88 \%)$ & \\
\hline M4,M5 & $1 / 24(4.2 \%)$ & $5 / 26(19.2 \%)$ & $6(12 \%)$ & $5 / 24(20.8 \%)$ & $1 / 26(3.8 \%)$ & $6(12 \%)$ & \\
\hline Total & $24 / 50(48 \%)$ & $26 / 50(52 \%)$ & $50(100 \%)$ & $24 / 50(48 \%)$ & $26 / 50(52 \%)$ & $50(100 \%)$ & \\
\hline CD34 & & & & 0.129 & & & 0.796 \\
\hline Negative & $10 / 14(71.4 \%)$ & $4 / 14(28.6 \%)$ & $14(100 \%)$ & $7 / 14(50 \%)$ & $7 / 14(50 \%)$ & $14(100 \%)$ & \\
\hline Positive & $14 / 36(39 \%)$ & $22 / 36(61 \%)$ & $36(100 \%)$ & $17 / 36(47.3 \%)$ & $19 / 36(52.7 \%)$ & $36(100 \%)$ & \\
\hline Total & $24 / 50(47.1 \%)$ & $26 / 50(52.9 \%)$ & $50(100 \%)$ & $24 / 50(47.1 \%)$ & $26 / 50(52.9 \%)$ & $50(100 \%)$ & \\
\hline CD117 & & & & 0.232 & & & 0.585 \\
\hline Negative & $11 / 19(58 \%)$ & $8 / 19(42 \%)$ & $19(100 \%)$ & $8 / 19(42 \%)$ & $11 / 19(58 \%)$ & $19(100 \%)$ & \\
\hline Positive & $13 / 31(42 \%)$ & $18 / 31(58 \%)$ & $31(100 \%)$ & $16 / 36(58.4 \%)$ & $15 / 36(41.6 \%)$ & $31(100 \%)$ & \\
\hline Total & $24 / 50(47.1 \%)$ & $26 / 50(52.9 \%)$ & $50(100 \%)$ & $24 / 50(47.1 \%)$ & $26 / 50(52.9 \%)$ & $50(100 \%)$ & \\
\hline
\end{tabular}

*Significant; TLC (Total leucocyte count), HB (Hemoglobin), Plts. (Platelet), PB (Peripheral blood), BM (Bone Marrow)

was achieved in $19 / 49$ patients $(38.7 \%)$ compared to $30 / 49$ (61.3\%) who failed to achieve CR after the first course of induction, with one missed patient in follow up. No statistical significant correlation was found between any of the clinical and hematological variables and response to therapy except for age $(\mathrm{p}=0.014)$. For patients who achieved CR $(15 / 19,78.9 \%)$ were <45years compared to those who had an age of $\geq 45$ years were $(4 / 19,21.1 \%)$ Table3.

Concerning the expression of BAALC and ERG genes with the response rate, among those who showed high BAALC expression $(9 / 26,35 \%)$ achieved CR compared to $(17 / 26,65 \%)$ that failed to achieve CR. In those who showed low BAALC expression (10/23, 43.5\%) achieved 
BAALC and ERG Genes as Prognostic Factors in Adult Myeloid Leukemia Patients, Egypt

CR compared to $(13 / 23,56.5 \%)$. However this difference couldn't reach a statistical significant level $(\mathrm{p}=0.676)$. Considering ERG expression, there was a statistical significant difference $(\mathrm{p}=0.028)$, patients who had high ERG expression $(6 / 26,23 \%)$, achieved CR compared to the $(20 / 26,77 \%)$ that failed to achieve CR. On the other hand, the patients that showed low ERG expression (13/23, $56.5 \%$ ) achieved CR compared to those (10/23, 43.5\%) who failed to achieve CR Table4, (Figure3).

Table 3. Relation of Clinical Parameters with Response to Therapy

\begin{tabular}{|c|c|c|c|}
\hline & \multicolumn{2}{|c|}{ Complete remission (No\%) } & P. Value \\
\hline \multirow{2}{*}{$\overline{\text { Age(Years) }}$} & $<45$ & $15 / 49$ & $0.014 *$ \\
\hline & $\geq 45$ & $4-21$ & \\
\hline \multirow[t]{2}{*}{ Sex } & Females & $10 / 26(43.5 \%)$ & 1 \\
\hline & Males & $9 / 24(37.5 \%)$ & \\
\hline \multirow[t]{2}{*}{ Lymphadenopathy } & Yes & $7 / 15(46.7 \%)$ & 0.529 \\
\hline & No & $12 / 35(37.5 \%)$ & \\
\hline \multirow[t]{2}{*}{ Splenomegaly } & Yes & $9 / 21(47.4 \%)$ & 0.556 \\
\hline & No & $10 / 29(35.7 \%)$ & \\
\hline \multirow[t]{2}{*}{ Hepatomegaly } & Yes & $8 / 25(36.4 \%)$ & 0.355 \\
\hline & No & $11 / 25(44.0 \%)$ & \\
\hline
\end{tabular}

*Significant

Table 4. BAALC and ERG Gene Expression and Response to Therapy

\begin{tabular}{llll}
\hline & $\begin{array}{l}\text { BAALC } \\
\text { High expression } \\
(\mathrm{n}=26)\end{array}$ & $\begin{array}{l}\text { BAALC } \\
\text { Low Expression } \\
(\mathrm{n}=24)\end{array}$ & P value \\
\hline CR & $9 / 26(35 \%)$ & $10 / 23(43.5 \%)$ & 0.643 \\
No response & $17 / 26(65 \%)$ & $13 / 23(56.5 \%)$ & 0.643 \\
& ERG & ERG & P value \\
& High expression & Low Expression & \\
CR & $(\mathrm{n}=26)$ & $(\mathrm{n}=24)$ & \\
No response & 6/26 $(23 \%)$ & $13 / 23(56.5 \%)$ & $0.028 *$ \\
*Significant; CR (complete Response) & & $0.028 *$ \\
\hline
\end{tabular}

Table 5. Relation of Age, BM Blasts, FAB Classification with Overall surviva

\begin{tabular}{|c|c|c|c|}
\hline Parameter & $\begin{array}{l}\text { Median Duration } \\
\text { of OS }\end{array}$ & $\begin{array}{l}18 \text { months } \\
(\%)\end{array}$ & Significance \\
\hline \multicolumn{3}{|l|}{ Age(Years) } & \multirow[t]{3}{*}{$<0.001 *$} \\
\hline$<45$ & 5.9 & 36 & \\
\hline$\geq 45$ & 1 & 0 & \\
\hline \multicolumn{3}{|l|}{ BM blasts } & \multirow[t]{3}{*}{$0.045^{*}$} \\
\hline$<75 \%$ & 5.3 & 22.6 & \\
\hline$\geq 75 \%$ & 1.6 & 22.1 & \\
\hline Myeloid & 3.9 & 24.9 & $0.041 *$ \\
\hline \multicolumn{2}{|c|}{ Myeloid with monocytic element } & 0.8 & 0 \\
\hline
\end{tabular}

Table 6. Relation of BAALC and ERG Gene Expression with Overall Survival

\begin{tabular}{lccc}
\hline & Median duration of OS & 18 months $\%$ & Significance \\
\hline BAALC: & & & \\
High & 2.6 & 8.9 & $0.008 *$ \\
Low & 5.5 & 36.4 & \\
ERG: & & & \\
High & 2.4 & 9.6 & $0.025 *$ \\
Low & 5.6 & 34.8 & \\
\hline
\end{tabular}

In our study, the 2 years survival was $19.7 \%$ with a median of 3.75 months. Among clinical and hematological variables only age (Figure4), BM blasts and FAB classification showed a statistical significant difference with median survival $(\mathrm{p}=<0.001,0.045$ and 0.041 respectively) Table5.

Finally, we analyzed the overall survival with the expression levels of BAALC and ERG genes. There was a statistical significant difference in their expression level with median survival ( $\mathrm{p}=<0.008$ and 0.025 respectively), in the group of patients with high BAALC expression $(26 / 50,52 \%)$, the median survival was 2.6 months compared to those patients with low expression level $(24 / 50,48 \%)$ their median survival was 5.52 months. In the same line, patients with high ERG expression (26/50, $52 \%$ ) had a median survival of 2.4 months compared to those patients with low ERG expression level (24/50, $48 \%$ ), their median survival was 5.6 months Table6

\section{Discussion}

Acute myeloid leukemia (AML) is a cytogenetically and molecularly heterogeneous disease characterized by clonal proliferation of myeloid precursors and maturation arrest, with accumulation of acquired genetic alterations in hematopoietic progenitor cells that disturb normal mechanisms of cell growth, proliferation and differentiation (Dohner 2005).

In recent years, the situation has become more complicated because of the description of several novel prognostic factors, including molecular markers such as gene mutations or changes in the level of gene expression to risk-stratify patients with AML. With the number of molecular markers increasing, it is important to investigate each of these markers not only separately but also in relation to each other.

In our study, we did not detect BAALC and ERG m-RNA transcripts, by real time RT-PCR, in normal bone marrow cells obtained from 10 healthy controls.

Our results is near to what was found by (Baldus et al., 2003; Baldus et al., 2006) in their 2 large studies (86 and 307 adult de novo AML patients) by the same technique (real time RT-PCR). They showed that BAALC transcripts were expressed in very low levels in unsorted bone marrow cells. They proved that BAALC expression is restricted to CD34+ hematopoietic progenitor cells by Immunohistochemistry, proved the granular cytoplasmic localization of the protein. So BAALC can be considered as a marker for lineage-committed and uncommitted hematopoietic progenitor cells.

On the same line, (Bienz et al., 2005; Yang et al., 2015) had found a low but detectable level of expression within the healthy normal controls for both genes.

In addition, the previous four articles studied the level of BAALC in both PB and BM, the first 2 studies revealed higher BAALC expression in BM as compared to $\mathrm{PB}$ while 3 rd one found no difference in both BM and PB.

Increasing our control size may help to detect higher level of expression. In addition, measurement of BAALC expression is recommended in peripheral blood to avoid contamination with CD34+ cells that physiologically 
express BAALC.

By using different techniques in gene expression, there is generally a good correlation between expression ratios measured by q PCR and by those obtained from oligonucleotide microarrays. However, most of the analysis relied on relative expression differences between samples and not on absolute expression levels (Draghici et al., 2006; Langer et al., 2008; Metzeler et al., 2009).

However, additional standardization of the methods used to determine both gene expression levels is important to establish a more sensitive and reliable technique for identification.

In this study a significant correlation was found between high BAALC and ERG gene expression with age $(p=0.004$ and 0.019 respectively). High BAALC and ERG expressers were included more in the group of patients $\geq 45$ years.

Our results are not consistent with that encountered by (Bienz et al., 2005; Metzeler et al., 2009) who found no significant difference between expression level of BAALC, ERG and age with a cut off of (60y) (median age of 49 and 59 years, respectively). However in a study of (Schwind et al., 2010), they found that older patients with favorable molecular risk factors, such as low BAALC and/or ERG expression, if treated more intensively, might have outcomes comparable with those of younger patients with corresponding molecular features.

So increasing our sample size with more age variation may confirm or exclude such correlation.

Regarding other clinical variables, no significant correlation was found between level of BAALC, ERG gene expression with sex, lymphadenopathy, splenomegaly and/or hepatomegaly.

About patients' hematological data, there was no statistical difference between high BAALC gene expression and TLC, HB level, Platelet count, PB and BM blasts.

This is consistent with (Baldus et al., 2006; Metzeler et al., 2009) except for the PB blasts, they found that patients with high BAALC expression showed higher percentage of circulating PB blasts.

As regarding the TLC, our results is in agreement with (Bienz et al., 2005) while on the contrary with (Metzeler et al., 2009) who found a statistical significant difference between high BAALC expressers and high TLC count.

Same results were obtained for ERG gene, there was no significant difference between high ERG gene expression and TLC, HB level, Platelet count, PB and BM blasts. Differences in sample size and techniques used to asses such genes may affect these differences.

According to FAB sub-classification of our AML patients, we found that those with M0, M1, M2 subtypes had higher levels of BAALC (although it did not reach a statistical significant level $)(\mathrm{p}=0.112)$, and $\mathrm{ERG}$ transcripts $(\mathrm{p}=0.058)$ (statistically significant). However, those with M4 and M5 had lower levels of BAALC and ERG transcripts.

Our finding is in accordance with (Baldus et al., 2003; Bienz et al., 2005; Baldus et al., 2006; Langer et al., 2008; Metzeler et al., 2009).

This proves that BAALC and ERG mainly belongs to
M0, M1, M2 FAB subtypes and less expressed in more differentiated subtypes of AML and may confirm partially the physiological expression of BAALC in CD34+ cells.

On the other hand there was no statistical significant correlation between BAALC and ERG gene expression with any of the immunophenotyping markers as CD34, CD117, or aberrant lymphoid markers.

These results do not go in line with (Heuser et al., 2005; Langer et al., 2008) who found that high BAALC expression was positively related with CD34 positive patients. The notion of BAALC as a marker of hematopoietic progenitor cells is further supported by other results as high BAALC expression was associated with genes found up-regulated in undifferentiated hematopoietic cells (CD 133, CD34, KIT, NPR3, JUP, C5orf23, FZD6, B4GALT6, CRYGD, PLAGL1, ITM2C) (Toren et al., 2005; Jaatinen et al., 2006; Langer et al., 2008).

A comprehensive study of large number of cases together with standardization of the technique used for measurement of BAALC gene is recommended to confirm this finding.

In our study, considering the response rate, although patients with high BAALC expression were less likely to achieve CR than those with low expression levels, however, this difference did not reach a statistically significant level( $\mathrm{p}=0.676)$.

In agreement with our study (Bienz et al., 2005; Baldus et al., 2006; Langer et al., 2008; Langer et al., 2009; Schwind et al., 2010; Eisfeld et al., 2012). In addition (Langer et al., 2009) stated that patients with high BAALC expression were almost twice as likely to die as those with low BAALC expression. He found together with (Santamaria et al., 2009; Schwind et al., 2010) that higher BAALC expression is associated with higher relapse rate, higher incidence of Flt-3 expression, higher ERG expression and other factors as the multidrug resistance gene ABCB1 (MDR1) were identified as highly up-regulated genes in high BAALC expressers, which is consistent with the resistant disease associated with these patients.

As for ERG, a statistical significant correlation was detected between level of ERG expression and response to therapy. Patients with high ERG expression failed to achieve CR compared to those with low expression levels. This result supports that ERG expression is a valuable predictor for clinical outcome in patients with AML and is consistent with reports in other types of cancer (i.e. T-cell acute lymphoblastic leukemia and prostate cancer) (Baldus et al., 2006; Wang et al., 2006).

Our findings is consistent with those reported by (Bienz et al., 2005; Marucci et al., 2005; Marucci et al., 2007; Metzeler et al., 2009; Santamaria et al., 2009; Schwind et al., 2010).

Regarding the overall survival, there was a statistical significant difference between both BAALC and ERG expression level and the overall survival. We found that patients with high BAALC expression predict a significantly inferior overall survival compared to those with low expression level. The same findings concerning high ERG expression compared to low expression levels 
were found.

Our findings is consistent with (Tanner et al., 2001; Baldus et al., 2003; Bienz et al., 2005; Marucci et al., 2005; Baldus et al., 2006; Langer et al., 2009; Metzeler et al., 2009; Santamaria et al., 2009; Schwind et al., 2010; Eisfeld et al., 2012).

Langer et al., 2009 by himself found that high BAALC expression predicted poor OS independently from other genes such as Flt-3 ITD, NPM1 and CEBPA mutation status. This suggests that high BAALC and ERG expressions emerged as a strong negative prognostic markers that independently predicted shorter survival and confirms the adverse prognostic impact of BAALC and ERG in AML.

Interaction between BAALC and ERG expression: Finally, because there is a complex prognostic network constituted by different molecular markers in AML, we analyzed in our study the interaction between BAALC and ERG gene expressions, and we found no statistical significant correlation between both genes. Our results is not in agreement with (Marucci et al., 2005; Marucci et al., 2007; Langer et al., 2008; Metzeler et al., 2009; Santamaria et al., 2009) who found an association between the high expression of both genes.

The biological interaction between different genes and the recently discovered micro RNAs, may be a part of this dis-accordance as stated by (Eisfeld et al., 2012). BAALC gene expression is associated with down-regulation of microRNA embedded in the HOX cluster (HOXA and HOXB gene) and up-regulation of miRNA-222, which is known to target the tyrosine kinase, KIT. BAALC gene is down-regulated in NPM1 mutated patients (Becker et al., 2010).

On the other side, low ERG gene expression is associated with up-regulation of topoisomerase I and miRNA-148a and down-regulation of DNA-methyltransferases which, by its turn, may lead to new therapeutic strategies in AML patients (Schwind et al., 2010).

In conclusion, our preliminary results for the analysis of the expression level of BAALC and ERG genes in bone marrow samples obtained from Egyptian AML patients showed both genes are specific significant molecular markers in disease progression, response to treatment and survival as well as might be of a potential use as target molecules in therapy. Additional studies of long-term clinical follow up and larger sample size are needed so that the statistical studies are more conclusive.

\section{References}

Baldus CD, Tanner SM, Kusewitt DF, et al (2003). BAALC, a novel marker of human hematopoietic progenitor cells. Exp Hematol, 31, 1051-56.

Baldus CD, Tanner SM, Ruppert AS, et al (2003). BAALC expression predicts clinical outcome of de novo acute myeloid leukemia patients with normal cytogenetics. A cancer and leukemia Group B study. Blood, 102, 1613-18.

Baldus CD, Burmeister T, Martus P, et al (2006). High expression of the ETS transcription factor ERG predicts adverse outcome in acute T-lymphoblastic leukemia in adults. Journal of Clinical Oncology, 24, 4714-20.

Baldus CD, Thiede C, Soucek S, et al (2006). BAALC expression and FLT3- internal tandem duplication mutations in acute myeloid leukemia patients with normal cytogenetics, prognostic implications. J Clin Oncol, 24, 790-97.

Becker H, Marcucci G, Maharry K, et al (2010). Favorable prognostic impact of NPM1 mutations in older patients with cytogenetically normal de novo acute myeloid leukemia and associated gene-and micro RNA-expression signatures. A Cancer and Leukemia Group B study. J Clin Oncol, 28, 596-604.

Bienz M, Ludwig M, Leibundgut EO, et al (2005). Risk assessment in patients with acute myeloid leukemia and a normal karyotype. Clin Cancer Res, 11, 1416-24.

Bing Xu, Guoshu Chen, Pengcheng Shi, et al (2012). shRNA - Mediated BAALC knockdown affects proliferation and apoptosis in human acute myeloid leukemia cells. Hematology, 17, 35-40.

Dohner H (2005). Implication of the molecular characterization of acute myeloid leukemia. Hematology, Am Soc Hemato Educ Program, 2007, 412-18.

Draghici S, Khatri P, Eklund AC, Szallasi Z (2006). Reliability and reproducibility issues in DNA microarray measurements. Trends Genet, 22, 101-9.

Eid MA, Attia M, Abdou S, et al (2010). BAALC and ERG expression in acute myeloid leukemia with normal karyotype: impact on prognosis. International Journal of Laboratory Hematology, 32, 197-205.

Eisfeld AK, Marcucci G, Liyanarachchi S, et al (2012). Heritable polymorphism predisposes to high BAALC expression in acute myeloid leukemia. Proc Natl Acad Sci USA, 109, 6668-73.

Heuser M, Wingen LU, Steinemann D, et al (2005). Gene expression profiles and their association with drug resistance in adult acute myeloid leukemia. Haematologica, 90, 1484-92.

Jaatinen T, Hemmoranta H, Hautaniemi S, et al (2006). Global gene expression profile of human cord blood - derived CD133+ cells. Stem cells, 24, 631-41.

Klezovitch O, Risk M, Coleman I, et al (2008). A causal role for ERG in neoplastic transformation of prostate epithelium. PNAS, 105, 2105-10.

Kong XT, Ida K, Ichikawa H, et al (1997). Consistent detection of TLS/FUS-ERG chimeric transcripts in acute myeloid leukemia with $\mathrm{t}(16 ; 21)(\mathrm{p} 11 ; \mathrm{q} 22)$ and identification of a novel transcript. Blood, 90, 1192-99.

Langer C, Radmacher MD, Ruppert AS, et al (2008). High BAALC expression associates with other molecular prognostic markers, poor outcome, and a distinct geneexpression signature in cytogenetically normal patients younger than 60 years with acute myeloid leukemia. A Cancer and Leukemia Group B (CALGB) study. Blood, 111, 5371-79.

Langer C, Marcucci G, Holland KB, et al (2009). Prognostic importance of MN1 transcript levels, and biologic insights from MN1- associated gene and microRNA expression signatures in cytogenetically normal acute myeloid leukemia. A cancer and leukemia group B study. J Clin Oncol, 27, 3198- 204.

Lichtman JD, Sternberg DW (2005). The molecular pathology of acute myeloid leukemia. Hematology, Am Soc Hematol Educ Program, 137-42.

Loughran SJ, Kruse EA, Hacking DF, et al (2008). The transcription factor Erg is essential for definitive hematopoiesis and the function of adult hematopoietic stem cells. Nat Immunol, 9, 810-9.

Marcucci G, Baldus CD, Ruppert AS, et al (2005). Overexpression of the ETS-related gene, ERG, predicts a worse outcome in acute myeloid leukemia with normal karyotype. A Cancer 
and Leukemia Group B study. J Clin Oncol, 23, 9234-42.

Marcucci G, Maharry K, Whitman SP, et al (2007). High expression levels of the ETS-related gene, ERG, predict adverse outcome and improve molecular risk-based classification of cytogenetically normal acute myeloid leukemia. A Cancer and Leukemia Group B Study. J Clin Oncol, 25, 3337-43.

Metzeler KH, Dufour A, Benthaus T, et al (2009). ERG expression is an independent prognostic factor and allows refined risk stratification in cytogenetically normal acute myeloid leukemia: a comprehensive analysis of ERG, MN1, and BAALC transcript levels using oligonucleotide microarrays. J Clin Oncol, 27, 5031-38.

Mrozek K, Marcucci G, Paschka P, Whitman SP, Bloomfield CD (2007). Clinical relevance of mutations and gene-expression changes in adult acute myeloid leukemia with normal cytogenetics, are we ready for a prognostically prioritized molecular classification? Blood, 109, 431-48.

Oikawa T, Yamada T (2003). Molecular biology of the ETS family of transcription factors. Gene, $\mathbf{3 0 3}, 11-34$.

Santamaría C, Chillón MC, García-Sanz R, et al (2009). BAALC is an important predictor of refractoriness to chemotherapy and poor survival in intermediate-risk acute myeloid leukemia (AML). Ann Hematol, 89, 453-8.

Schwind S, Marcucci G, Maharry K, et al (2010). BAALC and ERG expression levels are associated with outcome and distinct gene and microRNA expression profiles in older patients with de novo cytogenetically normal acute myeloid leukemia. A Cancer and Leukemia Group B study. Blood, 116, 5660-69.

Solomon S, Malkovska V (2005). Acute myeloid leukemia. In: Rodgers GP, Young NS, Eds. Lippincott, Williams and Wilkins pp. 135-50.

Sorensen PH, Lessnick SL, Lopez-Terrada D, et al (1994). A second Ewing's sarcoma translocation, $t(21 ; 22)$, fuses the EWS gene to another ETS-family transcription factor, ERG. Nature Genetics, 6, 146-51.

Tanner SM, Austin JL, Leone G, et al (2001). BAALC, the human member of a novel mammalian neuroectoderm gene lineage, is implicated in hematopoiesis and acute leukemia. Proc Natl Acad Sci USA, 98, 13901-6.

Taoudi S, Bee T, Hilton A, et al (2011). ERG dependence distinguishes developmental control of hematopoietic stem cell maintenance from hematopoietic specification. Genes Dev, 25, 251-62.

Toren A, Bielorai B, Jacob-Hirsch J, et al (2005). CD133-positive hematopoietic stem cell "stemness" genes contain many genes mutated or abnormally expressed in leukemia. Stem Cells, 23, 1142-53.

Vardiman JW, Thiele J, Arber DA, et al (2009). The 2008 revision of the World Health Organization (WHO) classification of myeloid neoplasms and acute leukemia: rationale and important changes. Blood, 114, 937.

Wang J, Cai Y, Ren C, Ittmann M (2006). Expression of variant TMPRSS2/ERG fusion messenger RNAs is associated with aggressive prostate cancer. Cancer Res, 66, 8347-51.

Yang L, Zhou JD, Zhang YY, et al (2015). Overexpression of BAALC, clinical significance in chinese de novo acute myeloid leukemia. Med Oncol, 32, 386-89. 